\title{
Non-arteritic anterior ischemic optic neuropathy versus cerebral ischemic stroke
}

\author{
Sohan Singh Hayreh
}

Received: 24 February 2012 /Revised: 25 March 2012 / Accepted: 3 April 2012 /Published online: 21 April 2012

(C) Springer-Verlag 2012

Non-arteritic anterior ischemic optic neuropathy (NAAION) is a common, visually disabling disease. However, its pathogenesis and management have been highly controversial. There is a common belief that NA-AION and cerebral ischemic stroke are similar in nature pathogenetically and in management. For example, ophthalmologists and neurologists routinely tend to prescribe aspirin to NAAION patients with the rationale that NA-AION, like stroke, is a thromboembolic disorder and aspirin helps thromboembolic disorders. NA-AION patients who come to consult me usually tell me that their neuro-ophthalmologists and neurologists have stated that NA-AION and cerebral ischemic stroke are similar in nature. This concept has resulted in major controversy on the pathogenesis and management of NA-AION. The evidence shows, however, that NA-AION is pathogenetically a totally different clinical entity from cerebral ischemic stroke.

It is well-established that cerebral ischemic stroke is a thromboembolic disorder in most cases. In a smaller number of cases, cerebral ischemic stroke can also be due to hypoperfusion and watershed infarcts when blood pressure drops to a critical level. My studies have shown that NA-AION, unlike most cases of cerebral ischemic stroke, is NOT a thromboembolic disorder, except very rarely [1-3]. Fluorescein fundus

\footnotetext{
S. S. Hayreh

Department of Ophthalmology and Visual Sciences, College of Medicine, University of Iowa, Iowa City, IA, USA

S. S. Hayreh $(\bowtie)$

Department of Ophthalmology and Visual Sciences, University Hospitals \& Clinics, 200 Hawkins Drive, Iowa City, IA 52242-1091, USA

e-mail: sohan-hayreh@uiowa.edu
}

angiography provides the crucial information about this, as is evident from the following.

The optic nerve head $(\mathrm{ONH})$ is supplied by the posterior ciliary artery $[4,5]$. First and foremost, if NA-AION were a thromboembolic disorder, fluorescein fundus angiography during the early stages of the onset of visual loss would invariably show evidence of complete occlusion of the posterior ciliary artery, with no filling of the $\mathrm{ONH}$ and the choroid. For example, in arteritic AION, due to giant cell arteritis, where there is complete occlusion of the posterior ciliary artery due to thrombosis [6-8], the $\mathrm{ONH}$ and choroid do not fill at all, as shown in Fig. 1. In sharp contrast to that, in my angiographic studies of more than 1,000 eyes with acute, classical NA-AION, no such occlusion was ever seen (except in a rare case when NA-AION was due to embolism to the posterior ciliary artery). Angiography soon after the onset of NA-AION may show only a transient hypoperfusion or non-perfusion of the peripapillary choroid and/or choroidal watershed zones, but these areas eventually fill with fluorescein during angiography, indicating no arterial occlusion and that NA-AION is not a thromboembolic occlusive disorder, as shown in Fig. 2. Fluorescein fundus angiography in Fig. 2 was performed during the day when the patient's blood pressure was normal, yet it still revealed a transient filling defect in the peripapillary choroid and watershed zone. My 24-hour ambulatory blood pressure monitoring studies in more than 700 patients have shown that in all normal persons, daytime blood pressure is in the normal range, but nevertheless there is always a variable degree of fall in blood pressure during sleep (see Figs. 3, 4). In the eye in Fig. 2, it is hypothesized that prolonged nonfilling of the peripapillary choroid (main source of blood supply to the $\mathrm{ONH}$ ) and the watershed zone surrounding the ONH during sleep, due to a fall of blood pressure, must have reduced blood flow to the $\mathrm{ONH}$ maximally, resulting in 


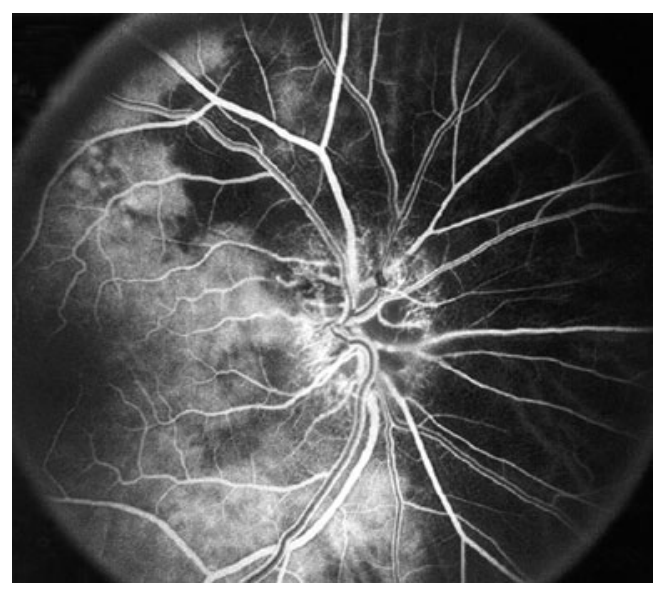

Fig. 1 Fluorescein fundus angiogram of right eye with arteritic AION, showing no filling of the nasal choroid and nasal $3 / 4$ of the optic nerve head, due to complete occlusion of the medial posterior ciliary artery. Reproduced from: Hayreh SS (1985) [7]

reduced perfusion pressure in the capillaries of the $\mathrm{ONH}$ below the critical autoregulatory range during sleep; that would result in transient ischemia of the $\mathrm{ONH}$ and development of NA-AION.

The severity of $\mathrm{ONH}$ ischemic damage depends upon the severity and the duration of ischemia, and this largely impacts the extent of recovery of visual function following the acute episode. For example, in arteritic AION there is thrombotic occlusion of the posterior ciliary artery and massive ischemic damage of the $\mathrm{ONH}$ and visual loss, with practically no visual improvement [9]. In NA-AION, by contrast, because there is only transient nonperfusion or hypoperfusion of the $\mathrm{ONH}$ circulation during sleep, $\mathrm{ONH}$ damage is usually much less severe and less extensive than in A-AION. Because of that reason, two large studies [10, 11] have shown that $41-43 \%$ of NA-AION eyes show spontaneous visual improvement.

Thus, my fluorescein fundus angiographic study during the acute stage of NA-AION (Fig. 2), and the spontaneous visual improvement in $41-43 \%[10,11]$ in NA-AION both

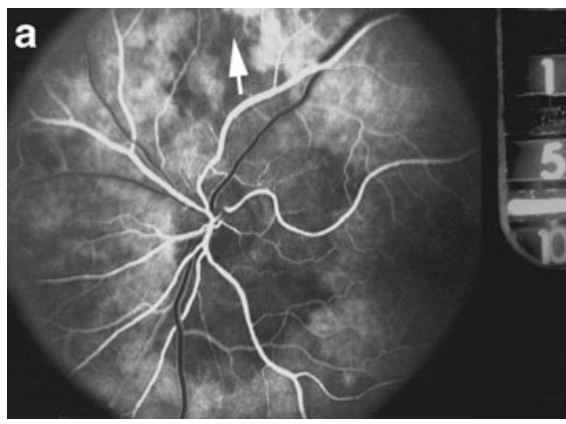

Fig. 2 Fluorescein angiograms of left eye 12 days after development of NA-AION[3]. a Angiogram 15 seconds after the injection of fluorescein shows no filling of the temporal, superior, and inferior peripapillary choroid (main source of blood supply to the $\mathrm{ONH}$ ), superior indicate that NA-AION is not a thromboembolic disorder. Naturally the question arises: what then is the mechanism of development of NA-AION? I have investigated the pathogenesis of NA-AION by basic, experimental, and clinical studies (in more than 1,000 NA-AION patients) [3].

\section{Pathogenesis of NA-AION}

I have discussed this previously [1, 2, 12], and at great length recently [3]. NA-AION is a multifactorial disease, i.e., a combination of many risk factors play a role in its development. The various risk factors can be divided into two types:

1. Predisposing risk factors: These make a person susceptible to develop NA-AION, but are not per se likely to produce it. These risk factors may be systemic or ocular.

(a) Systemic risk factors: These include diabetes mellitus [13], arterial hypotension, arterial hypertension, blood loss, sleep apnea, ischemic heart disease and other cardiovascular disorders, migraine, atherosclerosis, Type A personality, etc.

Studies have shown an association between sleep apnea and NA-AION [14-20]. Other studies indicate that there is an increase in sympathetic activity during sleep in patients with sleep apnea, even though these patients already have very high levels of sympathetic activity when awake $(P<0.001)$ [21]. Peak sympathetic activity (measured over the last 10 seconds of each apneic event) increased to $299 \pm$ $96 \%$ during stage II sleep and to $246 \pm 36 \%$ during REM sleep (both $P<0.001$ ) [21]. It is wellestablished that sympathetic activity causes vasoconstriction. That can work in two ways to produce NA-AION: (i) by causing vasoconstriction of vessels in the optic nerve head, which results in reduced blood supply, and (ii) more importantly,

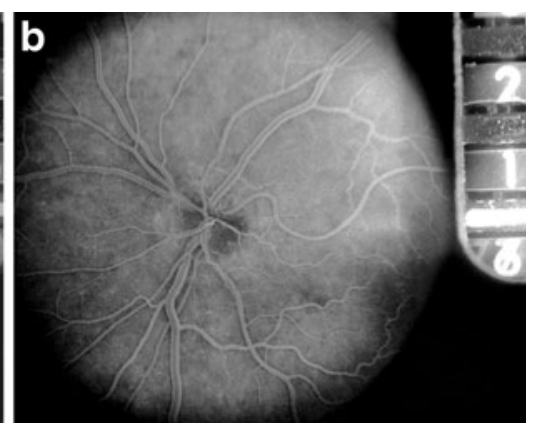

choroidal watershed zone (arrow), and the optic disc, with normal filling of both the medial and lateral posterior ciliary arteries. b Angiogram 6 seconds after a shows complete filling of the peripapillary choroid, the watershed zone, and upper part of the disc 
Fig. 3 Twenty-four-hour ambulatory blood pressure recording in a patient taking Verapamil (a calcium channel blocker). a When on $160 \mathrm{mg}$ morning and bedtime and $80 \mathrm{mg}$ at noon, during sleep systolic blood pressure dropped from $135 \mathrm{mg} / \mathrm{Hg}$ to $80 \mathrm{mg} / \mathrm{Hg}$ and diastolic from $70 \mathrm{~mm} / \mathrm{Hg}$ to about $35 \mathrm{mmHg}$. b On stopping the bedtime dose, nocturnal hypotension improved markedly a

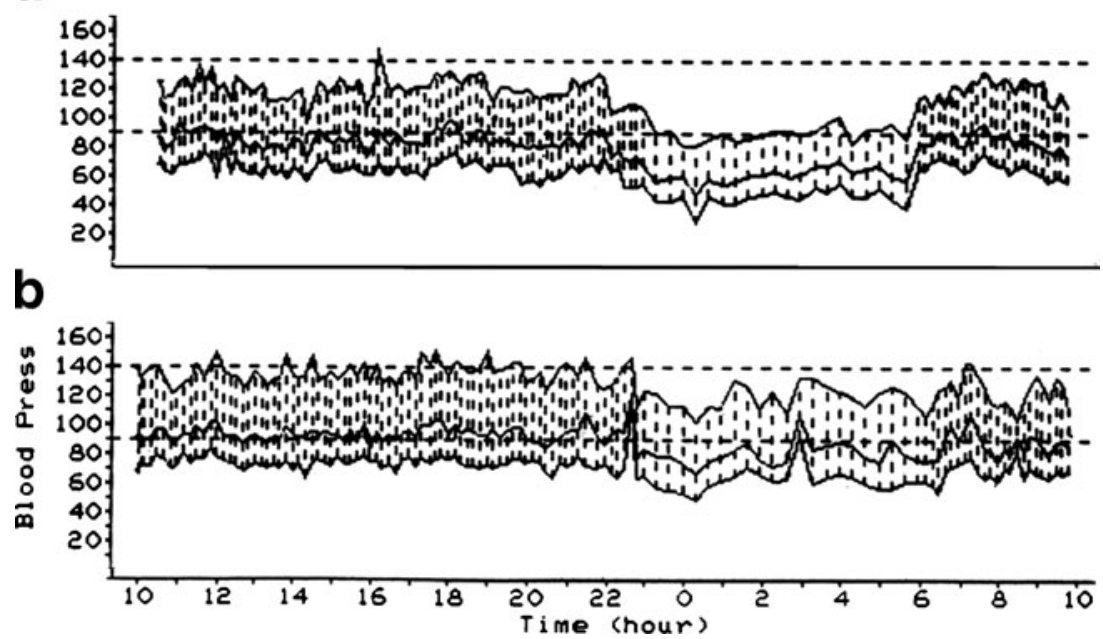

vasoconstriction of the terminal arterioles produces two paradoxical effects, which most people are unaware of - on the one hand, it results in a rise of blood pressure proximal to the constricted terminal arterioles because of increased vascular resistance (development of arterial hypertension that has been shown in patients with sleep apnea [21]), and on the other hand, constriction of terminal arterioles results in marked reduction of the blood pressure and flow in the capillaries distal to them. Thus, in patients with sleep apnea, during sleep the blood supply in the optic nerve head is deranged by two mechanisms: (a) vasoconstriction of the vessels in the optic nerve head, and (b) fall of blood pressure in its capillaries caused by constriction of the terminal arterioles. That results in development of NA-AION. A similar mechanism may be operating in patients with Type A personality who develop NA-AION, because they experience increased levels of plasma catecholamines under stress [22, 23]

(b) Ocular risk factors: These include poor $\mathrm{ONH}$ blood supply, posterior ciliary artery disease, location of the watershed zone of the posterior ciliary artery watershed zone in relation to the ONH [24], defective autoregulation and other factors that influence the blood flow in the ONH [25], absent or small optic disc cup, vasospasm, raised intraocular pressure, chronic optic disc edema, optic disc drusen, etc.

2. Precipitating risk factor(s): Our studies have shown that the time of a patient's first discovery of visual loss in NA-AION is a critical piece of information, because it provides an important clue about its pathogenesis [26]. In our prospective study [26] of 925 episodes of NAAION, $73 \%$ of patients gave a history, when specifically asked, of discovering their visual loss on awakening in the morning or from a nap, or at the first

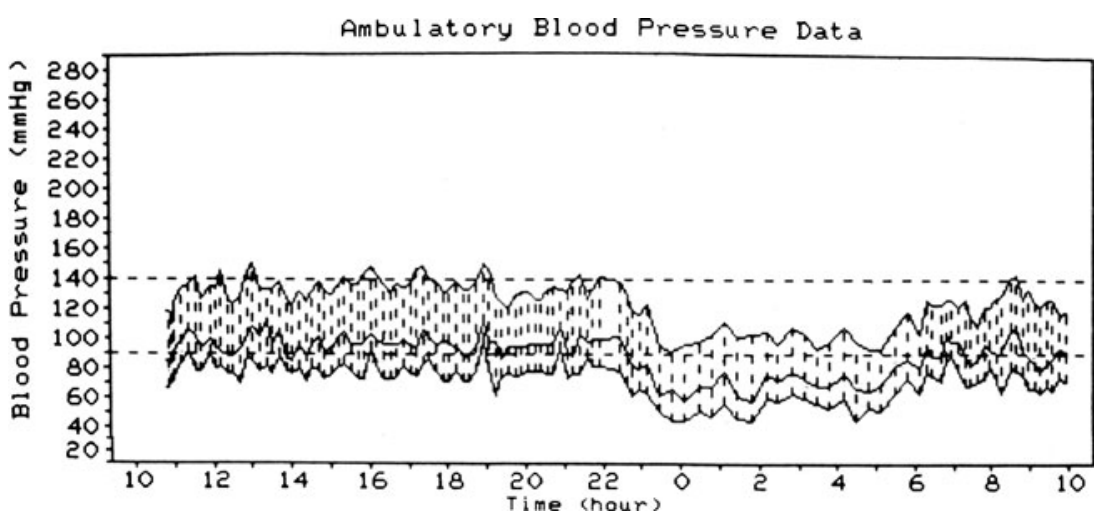

Fig. 4 Twenty-four-hour ambulatory blood pressure recording in a patient who developed NA-AION first in one eye and later on in the second eye. This patient was not on any medication, and yet showed marked nocturnal arterial hypotension, with drop of systolic blood pressure from $140 \mathrm{mmHg}$ during the day to as low as $90 \mathrm{~mm} \mathrm{Hg}$ during sleep, and diastolic blood pressure from about $80 \mathrm{mmHg}$ during the day to about $50 \mathrm{mmHg}$ during sleep. Reproduced from: Hayreh et al. (1999) Role of nocturnal arterial hypotension in optic nerve head ischemic disorders. Ophthalmologica 213:76-96 
opportunity in the day to use their vision critically. The incidence may actually be much higher than $73 \%$ because other patients, who first became aware of their visual loss later in the day, could not be certain when it had first occurred nor could they rule out the possibility that it had been there since awakening.

The argument put forward, by persons who doubt the role of nocturnal arterial hypotension in NA-AION and NA-AION as a hypotensive disorder, is that in the prospective NA-AION Multicenter Decompression Trial Study [10] only $42 \%$ of the 418 patients reported the onset of visual loss within 2 hours of awakening. This is in sharp contrast to the above findings of our prospective study [26]. The findings of these two prospective studies do conflict, and that has resulted in controversy on the important concept of the hypotensive nature of NA-AION, discussed below. But study design determines the quality of the data, whether it is a prospective study or not. The accuracy of this historical information can be largely influenced by: (i) the expertise of the person asking the questions, and (ii) the manner in which a patient is asked about when their visual loss was first noticed and the circumstances of how they became aware of it. In our study [26], I collected the historical information from each patient with NA-AION myself, and learned over time that the accuracy of a patient's recall depends upon non-suggestive, unbiased, yet thorough questioning. Often the patient needs to be made aware of the importance of their recollection of their discovery of visual loss. In the NA-AION Multicenter Decompression study [10], historical information was collected by many individuals at different study sites, by necessity, and may not be as rigorous as in my study. It is more challenging in such studies to collect such historical information methodically and uniformly enough to estimate the true proportion of patients whose visual loss occurred soon after awakening. Estimates of visual loss on awakening in patients with NA-AION can be largely underestimated if based on primarily what the patients volunteer, rather than the answers to specific, directed questioning. Moreover, the criterion used in that study of onset of visual loss occurring within 2 hours of awakening was not valid, because it all depends upon when the patients first tried to use their vision critically during the day. I think that explains the important discrepancy between our study [26] and that of the NA-AION Multicenter Decompression Trial Study [10].

The next question is: what can happen during sleep which can play a significant role in the development of NA-AION? We [27] performed 24-hour ambulatory blood pressure monitoring in patients with NAAION. That study showed that patients with arterial hypertension taking oral hypotensive therapy have a significant association between progressive visual field deterioration in NA-AION and nocturnal arterial hypotension [27]. This was because those patients with visual field progression had a mean minimum night-time systolic blood pressure significantly lower $(P=0.0185)$ than those without visual field deterioration. In addition, patients with NA-AION had a significantly larger mean decrease $(P=0.0011)$ and a mean percentage decrease $(P=0.0012)$ in systolic blood pressure, and mean decrease $(P=0.0079)$ and mean percentage decrease $(P=0.0315)$ in diastolic blood pressure during hours of sleep. This indicates that oral hypotensive therapy in hypertensives in such cases produced nocturnal arterial hypotension.

The fall of blood pressure during sleep is a physiological phenomenon. My 24-hour ambulatory blood pressure monitoring studies in more than 700 patients have shown that arterial hypotensive drugs taken at bedtime cause a far more marked degree of nocturnal arterial hypotension than when taken in the morning, because they aggravate the natural fall of blood pressure during sleep, as shown in Fig. 3. Some patients, however, develop marked nocturnal hypotension even without any medication, as seen in Fig. 4 (presumably due to defective cardiovascular autoregulation). Nocturnal hypotension may trigger the development of NA-AION in persons with other predisposing risk factors (mentioned above). For example, I have seen patients who developed NA-AION soon after starting to take terazosin hydrochloride (for benign prostatic hypertrophy) or other hypotensive drugs, including medications for erectile dysfunction [28] at bedtime.

What role does nocturnal arterial hypotension play in the development of NA-AION? As fully discussed elsewhere $[1-3,12]$ and mentioned above, NA-AION is a multifactorial disease, with many risk factors acting in various combinations, some as predisposing risk factors, making an $\mathrm{ONH}$ susceptible to ischemia, and some as precipitating factors. Available evidence indicates that for an $\mathrm{ONH}$ with predisposing risk factors, nocturnal arterial hypotension acts as the final insult ("the last straw"), resulting in ischemia of the $\mathrm{ONH}$ and NA-AION during sleep. Also, our study [29] of ipsilateral recurrence of NAAION (in 594 consecutive patients, 829 eyes) showed that overall patients with ipsilateral recurrence of NAAION had a significantly lower mean nighttime diastolic blood pressure $(P=0.003)$ and greater mean percentage drop during sleep in diastolic blood pressure $(P=0.011)$ than those with no recurrence of NA-AION. Thus, the study indicated that nocturnal arterial hypotension was a significant risk factor in ipsilateral recurrence of NA-AION. All this evidence indicates that nocturnal arterial hypotension plays an important role in the development of NA-AION and that NA-AION is 
a hypotensive disorder.

The available evidence indicates that a host of systemic and local factors, acting in different combinations and to different extents may reduce blood flow in the ONH circulation, with some factors making the ONH susceptible to ischemia, and others acting as the final insult. Nocturnal arterial hypotension seems to be an important precipitating factor in the susceptible patient [1-3, 26]. Thus, from this it can be inferred that NA-AION is a hypotensive disorder, with a transient hypoperfusion or nonperfusion of the $\mathrm{ONH}$ due to nocturnal arterial hypotension, resulting in anoxia of the ONH (Fig. 2), and not a thromboembolic disorder [2, 3].

Furthermore, the following differences between NA-AION and cerebral ischemic stroke indicate that the two are different clinical entities pathogenetically and for management.

1. There is a great volume of literature showing a significant association between smoking and cerebrovascular accident (a thromboembolic disorder) [30]. In contrast to that, two large prospective studies have shown no association between smoking and NA-AION (a hypotensive disorder) [31, 32].

2. Treatment of a disease is based on its pathophysiology. It is well-established that cerebral ischemic stroke mostly is a thromboembolic disorder, and aspirin has been shown to have beneficial effect in it. In sharp contrast to that, two large studies have shown that aspirin has no beneficial effects in NAAION [31, 33], nor on preventing another episode in the opposite eye. This is because aspirin has no effect on blood pressure. Moreover, long-term use of aspirin can cause serious systemic bleeding complications.

3. Studies have shown that in ischemic stroke (a thromboembolic disorder) systemic corticosteroid therapy has no beneficial effect and can even be detrimental [34-37]. Assuming that ischemic stroke and NA-AION are similar in nature, some authors [36] have concluded that "Steroids should not be offered to patients with nonarteritic anterior ischemic optic neuropathy". On the contrary, studies [38-40] have shown that corticosteroid therapy can have a beneficial effect in NA-AION (a hypotensive disorder). In my prospective study [40], NA-AION patients (312 patients) treated within 2 weeks of the onset of visual loss with high-dose systemic corticosteroids therapy showed significant improvement in visual acuity $(P=0.001)$ and visual field $(P=0.005)$ compared to a similar untreated group (301 patients).
I think it is appropriate to discuss briefly some concerns raised by skeptics in neuro-ophthalmology with regard to the above conclusion of my study [40], although I have discussed and responded to those at length elsewhere [3, 41]. Briefly, the prevailing impression among neuro-ophthalmologists that corticosteroid therapy in NA-AION has no beneficial effect is based on a series of misconceptions, including the following:

(i). That there is no rationale for giving corticosteroids in NA-AION. This is not valid. I have discussed in detail the scientific rationale for the use and beneficial effect of corticosteroid therapy [3, 40, 41]. Briefly, corticosteroid therapy reduces optic disc edema, which results in improved circulation in the optic nerve head and improvement in visual outcome.

(ii). That a few published reports failed to show any beneficial effect of corticosteroid therapy in NAAION. Those reports were seriously flawed. In them, corticosteroid therapy was given timidly, "too small a dose, for too short a period" or often too late. The treatment protocol for systemic corticosteroid therapy used in my study was very different, and essential to get the required benefit. To have a beneficial effect, corticosteroids must be given initially within first 2 weeks in high doses, and gradually tapered off over the duration of the optic disc edema, which usually lasts for about 2 months [40].

(iii). There is a prevailing misconception that since corticosteroid therapy is ineffective in ischemic cerebral stoke [34-37], it is also ineffective in NA-AION. Since ischemic cerebral stoke and NA-AION are different clinical entities pathogenetically and in management, there is no reason why their response to corticosteroid therapy should be the same.

4. Our study [26] showed seasonal differences in the onset of NA-AION compared to the onset of ischemic cerebral stroke. NA-AION onset was significantly more frequent in the (Iowa) summer than in the winter $(P=0.0030)$. This contrasts to the reported increased incidence of cerebrovascular accidents during the winter, compared to other seasons [26].

Thus, available evidence indicates that it is inaccurate to equate NA-AION with cerebral ischemic stroke. Explaining the pathogenesis and recommending management by extrapolating findings from one organ to another can be a dangerous practice. 
Acknowledgments Supported by grant EY-1151 from the National Institutes of Health, Bethesda, Maryland, and in part by unrestricted grant from Research to Prevent Blindness, Inc., New York.

\section{References}

1. Hayreh SS (1996) Acute ischemic disorders of the optic nerve: Pathogenesis, clinical manifestations and management. Ophthalmol Clin N Am 9:407-442

2. Hayreh SS (2009) Ischemic optic neuropathy. Prog Retin Eye Res 28:34-62

3. Hayreh SS (2011) Ischemic optic neuropathies. Springer-Verlag, Heidelberg

4. Hayreh SS (1969) Blood supply of the optic nerve head and its role in optic atrophy, glaucoma and oedema of the optic disc. Br J Ophthalmol 53:721-748

5. Hayreh SS (2001) The blood supply of the optic nerve head and the evaluation of it - Myth and reality. Prog Retin Eye Res 20:563593

6. Hayreh SS (1974) Anterior ischaemic optic neuropathy II. Fundus on ophthalmoscopy and fluorescein angiography. Br J Ophthalmol 58:964-980

7. Hayreh SS (1985) Inter-individual variation in blood supply of the optic nerve head. Its importance in various ischemic disorders of the optic nerve head, and glaucoma, low-tension glaucoma and allied disorders. Doc Ophthalmol 59:217-246

8. Hayreh SS (1990) Anterior ischaemic optic neuropathy: differentiation of arteritic from non-arteritic type and its management. Eye 4:25-41

9. Hayreh SS, Zimmerman B, Kardon RH (2002) Visual improvement with corticosteroid therapy in giant cell arteritis: report of a large study and review of literature. Acta Ophthalmol Scand $80: 355-367$

10. Ischemic Optic Neuropathy Decompression Trial Research Group (1995) Optic nerve decompression surgery for nonarteritic anterior ischemic optic neuropathy (NAION) is not effective and may be harmful. JAMA 273:625-632

11. Hayreh SS, Zimmerman MB (2008) Non-arteritic anterior ischemic optic neuropathy - natural history of visual outcome. Ophthalmology 115:298-305

12. Hayreh SS, Joos KM, Podhajsky PA, Long CR (1994) Systemic diseases associated with non-arteritic anterior ischemic optic neuropathy. Am J Ophthalmol 118:766-780

13. Hayreh SS, Zimmerman MB (2008) Nonarteritic anterior ischemic optic neuropathy: clinical characteristics in diabetic patients versus nondiabetic patients. Ophthalmology 115:1818-1825

14. Mojon DS, Hedges TR 3rd, Ehrenberg B et al (2002) Association between sleep apnea syndrome and nonarteritic anterior ischemic optic neuropathy. Arch Ophthalmol 120:601-605

15. Behbehani R, Mathews MK, Sergott RC, Savino PJ (2005) Nonarteritic anterior ischemic optic neuropathy in patients with sleep apnea while being treated with continuous positive airway pressure. Am J Ophthalmol 139:518-521

16. Palombi K, Renard E, Levy P et al (2006) Non-arteritic anterior ischaemic optic neuropathy is nearly systematically associated with obstructive sleep apnoea. Br J Ophthalmol 90:879-882

17. Li J, McGwin G Jr, Vaphiades MS, Owsley C (2007) Non-arteritic anterior ischaemic optic neuropathy and presumed sleep apnoea syndrome screened by the Sleep Apnea scale of the Sleep Disorders Questionnaire (SA-SDQ). Br J Ophthalmol 91:1524-1527

18. McNab AA (2007) The eye and sleep apnea. Sleep Med Rev 11:269-276
19. Waller EA, Bendel RE, Kaplan J (2008) Sleep disorders and the eye. Mayo Clin Proc 83:1251-1261

20. Nieto Enriquez J, Torres Blanch J, Badal Lafulla J (2009) Manifestaciones oculares del sindrome de apnea del sueno. [Ocular disease in sleep apnea syndrome]. Med Clin (Barc) 133:594-598

21. Somers VK, Dyken ME, Clary MP, Abboud FM (1995) Sympathetic neural mechanisms in obstructive sleep apnea. J Clin Invest 96:1897-1904

22. Howard JH, Rechnitzer PA, Cunningham DA et al (1990) Type A behavior, personality, and sympathetic response. Behav Med 16:149-160

23. Fredrikson M, Blumenthal JA (1992) Serum lipids, neuroendocrine and cardiovascular responses to stress in healthy Type A men. Biol Psychol 34:45-58

24. Hayreh SS (1990) In vivo choroidal circulation and its watershed zones. Eye 4:273-289

25. Hayreh SS (2001) Blood flow in the optic nerve head and factors that may influence it. Prog Retin Eye Res 20:595-624

26. Hayreh SS, Podhajsky PA, Zimmerman B (1997) Non-arteritic anterior ischemic optic neuropathy - time of onset of visual loss. Am J Ophthalmol 124:641-647

27. Hayreh SS, Zimmerman MB, Podhajsky P, Alward WLM (1994) Nocturnal arterial hypotension and its role in optic nerve head and ocular ischemic disorders. Am J Ophthalmol 117:603-624

28. Hayreh SS (2008) Non-arteritic anterior ischaemic optic neuropathy and phosphodiesterase-5 inhibitors. Br J Ophthalmol 92:15771580

29. Hayreh SS, Podhajsky PA, Zimmerman B (2001) Ipsilateral recurrence of nonarteritic anterior ischemic neuropathy. Am J Ophthalmol 132:734-742

30. Dagenais GR, Yi Q, Lonn E, HOPE Trial Investigators et al (2005) Impact of cigarette smoking in high-risk patients participating in a clinical trial. A substudy from the Heart Outcomes Prevention Evaluation (HOPE) trial. Eur J Cardiovasc Prev Rehabil 12:75-81

31. Newman NJ, Scherer R, Langenberg P, Kelman S, Feldon S, Kaufman D, Dickersin K (2002) The fellow eye in NAION: report from the ischemic optic neuropathy decompression trial follow-up study. Am J Ophthalmol 134:317-328

32. Hayreh SS, Jonas JB, Zimmerman MB (2007) Non-arteritic anterior ischemic optic neuropathy and tobacco smoking. Ophthalmology 114:804-809

33. Beck RW, Hayreh SS, Podhajsky PA, Tan E-S, Moke PS (1997) Aspirin therapy in nonarteritic anterior ischemic optic neuropathy. Am J Ophthalmol 123:212-217

34. Qizilbash N, Lewington SL, Lopez-Arrieta JM (2002) Corticosteroids for acute ischaemic stroke. Cochrane Database Syst Rev. (2):CD000064

35. Davis SM (2005) Medical management of haemorrhagic stroke. Crit Care Resusc 7:185-188

36. Biousse V (2010) Steroids should not be offered to patients with nonarteritic anterior ischemic optic neuropathy. J NeuroOphthalmol 30:194-195

37. Sandercock PS, Soane T (2011) Corticosteroids for acute ischaemic stroke. Cochrane Database Syst Rev. 9:CD000064

38. Foulds WS (1969) Visual disturbances in systemic disorders: optic neuropathy and systemic disease. Trans Ophthalmol Soc UK 89:125-146

39. Hayreh SS (1974) Anterior ischaemic optic neuropathy III. Treatment, prophylaxis, and differential diagnosis. $\mathrm{Br} \mathrm{J}$ Ophthalmol 58:981-989

40. Hayreh SS, Zimmerman MB (2008) Non-arteritic anterior ischemic optic neuropathy: role of systemic corticosteroid therapy. Graefes Arch Clin Exp Ophthalmol 246:1029-1046

41. Hayreh SS (2010) Role of steroid therapy in nonarteritic anterior ischemic optic neuropathy. J Neuro-Ophthalmol 30:388-389 